\title{
Detailed procedure for outdoor measurement of raindrop size distribution using photogrammetry
}

\author{
Zahra Abdollahii ${ }^{1,2}$, Seyed Hamidreza Sadeghi ${ }^{1 *}$, Abdulvahed Khaledi Darvishan ${ }^{1}$ \\ ${ }^{1}$ Department of Watershed Management Engineering, Faculty of Natural Resources and Marine Sciences, Tarbiat Modares University, \\ Noor4641776489, Mazandaran, Iran. E-mails: zahrabdollahi@modares.ac.ir; sadeghi@modares.ac.ir; a.khaledi@modares.ac.ir \\ 2 At present, Soil Conservation and Watershed Management Research Department, Zanjan Agricultural and Natural Resources Research \\ and Education Center, AREEO, Zanjan, Iran. \\ * Corresponding author. E-mail: sadeghi@modares.ac.ir
}

\begin{abstract}
Kinetic energy and corresponding erosive force of rainfall are strongly influenced by raindrop. The present paper aims to explore the raindrop size variation during rainfall events with different intensities in northern Iran by applying the processes of camera-taken photographs. Five rainfall intensities of 1 to $10 \mathrm{~mm} \mathrm{~h}^{-1}$ that occur frequently in the study area were analyzed. A camera with a very short exposure time was used to record the distribution of raindrops size. The raindrops diameters of the rain events ranged from $<0.2$ to $5.1 \mathrm{~mm}$ while the majority of them were between 1 and $2 \mathrm{~mm}$. The results also showed that the variation of rainfall intensity significantly influenced $(\mathrm{P}<0.05)$ raindrops size. Image processing was proven as an accurate technique of translation between the human visual system and digital imaging devices. The findings of the study can be practically utilized by researchers who work in the field of soil erosion and meteorology.
\end{abstract}

Keywords: Raindrop Size Distribution; Image processing; Rainfall Intensity; Rain Erosivity.

\section{INTRODUCTION}

Knowledge of the rainfall characteristics such as intensity, duration, frequency and raindrop size distribution (DSD) and their variations in time and space is important to better conceptualize the hydrological behavior of a watershed system (Molina-Sanchis et al., 2016). Raindrop size and its distribution are the key rainfall properties influencing soil erosion (Jwa et al., 2020; Khaledian and Shahoe, 2006; Serio et al., 2019). They exhibit pronounced temporal and spatial variations (Sreekanth et al., 2017). Drop terminal velocity, kinetic energy, and erosivity are strongly influenced by drop size (Serio et al., 2019). Raindrops fall on soil surface, causing soil particles to be broken down and dispersed. A rainfall event comprises a range of drop sizes and drop terminal velocities in stable weather conditions and bigger drops beget more energy and erosivity.

Marshall and Palmer (1948) gave the first analytical description of DSD, and their results are still widely used. After that, various researches have been using many different techniques to measure properties of raindrops. These techniques include the stain method (Sadeghi et al., 2013; Seginer, 1963; Hall, 1970; Solomon et al., 1985), flour method (DeBoer et al., 2001; Eigel and Moore, 1983; Kathiravelu et al., 2016; Laws and Parsons, 1943; Sadeghi et al., 2013), the photography method (King et al., 2014; Lima et al., 2015; McIsaac, 1990; Sadeghi et al., 2013; Salvador et al., 2009; Sudheer and Panda, 2000), the radar technique (Bringi et al., 2003; Tang et al., 2014; You et al., 2016; Zhang et al., 2001), the oil immersion techniques (Eigel and Moore, 1983), the stroboscope technique (Illingworth and Stevens, 1987; Lavergnat and Gole, 1998; Salles and Poesen, 1999), the optical array probe (Jash et al., 2019; Lilley et al., 2006; Wang et al., 2021) and disdrometers (Angulo-Martínez et al., 2016; Bringi et al., 2003; Das et al., 2017; Illingworth and Stevens, 1987; Jwa et al., 2020; Serio et al., 2019; Sheppard and Joe, 1994; Sulochana et al., 2016). The stain method, flour, and oil immersion techniques are time- consuming and record data temporarily (Sadeghi et al., 2013), while the photographic method can capture a scaled image of drops in flight and provide a direct measurement to determine the size of individual drops (Cruvinel et al., 2017; Chang et al., 2019; Frank et al., 1994; Sijs et al, 2021; Steinmann et al., 2021). However, the limited ability of the eye to distinguish total drops on an image and visual interpretation are considered as the sources of errors (Cruvinel et al., 2017; Frank et al., 1994; King et al., 2014; Sudheer and Panda, 2000). Automatic sampling devices provided continuous records are costly, complicated and inconvenient for routine use (Jayawardena and Rezaur, 2000). The advanced devices such as the optical disdrometer (Meshesha et al., 2017), the 2D-video disdrometer (D'Adderio et al., 2018; Thurai et al., 2009; Thurai et al., 2017) and Joss-Waldovgel disdrometer (Islam et al., 2012; Sreekanth et al., 2017) provided automatic records of DSD, and supply the continuous data for meteorological studies of cloud physic mainly on higher levels above the ground. However, they are presently too sophisticated, not applicable anywhere and too expensive for routine studies, e.g. of soil erosion (Jayawardena and Rezaur, 2000). According to Salvador et al. (2009), these devices have specific sources of errors such as those induced by side-passing drops and overlapping drops. In addition, Salvador et al. (2009), who used disdrometer to analyzed the drop velocity, found it exposed to large experimental errors (Chang et al., 2020).

Our study aims to measure the drop size distribution (DSD) in Mazandaran Province in north of Iran close to the Caspian Sea using a Digital Single-Lens Reflex (DSLR) camera with a very short exposure time. Such camera is a commonly available device that can quickly provide sufficient data for evaluation of the applicability of image processing in drop size determination for different rainfall intensities in natural conditions. Our study is based on successive digital color images in unstable rainfall intensities that include color information for each pixel that can be processed by any imaging software. 


\section{MATERIALS AND METHODS}

The study was conducted at the Faculty of Natural Resources, Tarbiat Modares University, Noor, Mazandaran Province, Iran (Fig. 1). This region has a variable climate; mild and humid climate of Caspian shoreline and the moderate and cold climate of mountainous regions. The experiment station is located in Noor City ( $36^{\circ} 34^{\prime} 42^{\prime \prime} \mathrm{N} ; 51^{\circ} 48^{\prime} 17^{\prime \prime}$ E; Elevation: $12 \mathrm{~m}$ a.s.1.). The climate ranges from humid to very humid (Asadpour and Habibi, 2015) with mean annual rainfall around $1000 \mathrm{~mm}$ (Yousefi et al., 2018). In this study, an open rainfall observation site was established and four rainfall events were monitored during the autumn.

An hourly-based dataset was collected for the analysis. Rainfall intensity was measured with a cylindrical vessel with a sharp edge and a uniform cross-section diameter of $10 \mathrm{~cm}$, i.e. the orifice area of about $314 \mathrm{~cm}^{2}$. Rain water was entering through the orifice and accumulated in the cylindrical vessel. The vessels were weighed at regular intervals of one hour during rainfall events and the amount of precipitation was determined by subtracting the vessel weight from the total weight. The gauge was placed in an open area where there were no obstructions nearby. Five rainfall intensities of one to $10 \mathrm{~mm}$ $\mathrm{h}^{-1}$ (more frequent intensities that occurs in the study area) were analyzed (Table 1). The distribution of raindrop size in each term was then recorded by photographic method as a practical method where no further particular instruments or technical facilities/experts are available.

Photographs of the raindrops were taken with the Canon 550D camera (resolution 18.7 Megapixels) with the shutter speed of $1: 4000^{\text {th }}$ of a second. Shutter speed is one of several methods used to control the amount of light recorded by the camera's digital sensor. Since appropriate exposure was required a very bright light was provided to the experimental set up to be able to take clear photos (Kavian et al., 2018). Therefore, two common photographic light sources were used. The direction of the light in each shooting was empirically adjusted by trial and error in order to produce the desired illumination. There were two possible error sources in this method; the depth of field effect and the ambiguity in defining the boundaries of the particles. Depth of field refers to the distance range of distance within that the photographs remains acceptably sharp around the focal point. The depth of field does not abruptly change from sharp in the focal point to unsharp in an area out of the focus zone but occurs as a gradual transition (Kuthirummal, et al., 2010). Fig. 2 shows a schematic of the depth of field and gradual transition from the focal point to out of the focus zone in forward and backward of the focal point. The transition has been exaggerated for more clarity in Fig. 2; in reality, this would be only a tiny fraction of the camera sensors area.

Therefore, a focal point was needed to focus the camera so that the raindrops are sharp in the photographs. A $50 \mathrm{~cm} \times 30$ $\mathrm{cm}$-frame was used with a $5 \mathrm{~cm} \times 5 \mathrm{~cm}$ board fixed at its center as a focal plane for the photography and installed at a height of 1.5 meters above the ground to catch identified data. A shallow depth of field was needed to isolate some distinct drops from the remaining environment. There are four factors affecting depth of field, i.e. the aperture, the distance between the camera and the subject, focal length, and camera sensor size (Lilley et al., 2006; Perwass and Wietzke, 2012), the appropriate information has been briefly presented in Fig. 2b. Therefore, the focal length and aperture of $75 \mathrm{~mm} \mathrm{f} / 1.8$ from the distance of one meter were set in the camera setting to create a slim area in front and behind the focus point of around $1-2 \mathrm{~cm}$. There are different methods to calculate the depth of field (Luo et al., 2013). We used the online depth of field calculator to set the camera (http://www.dofmaster.com).

The second possible error was the ambiguity in defining the boundaries of the particles. The ambiguity increased, as the particles were located farther from the focal plane. To provide better and natural contrast between drops and background, a black sheet was set as background of the photography for rain events which occurred during the daylight. A schematic view of the experimental arrangement and a sample of a digitized image of drops captured by the high-speed camera with a very short exposure time is given in Fig. 3. The calibration procedure has been shown in Fig. 4.
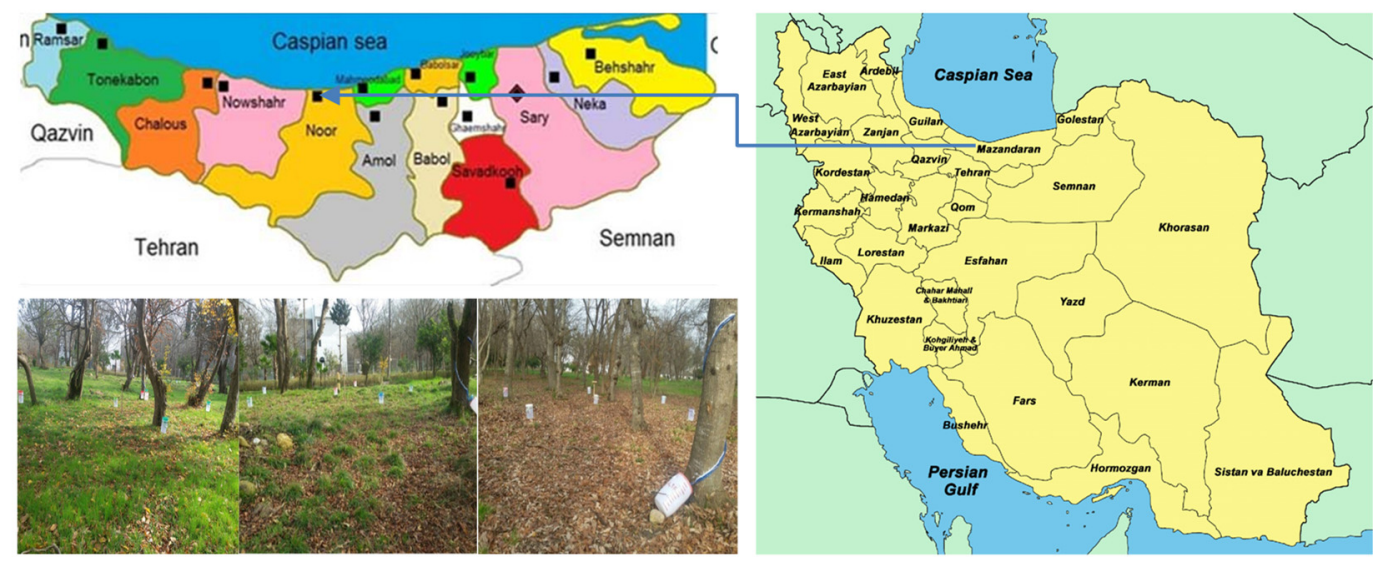

Fig. 1. Site location, the Faculty of Natural Resources, Tarbiat Modares University, Noor, Iran.

Table 1. Rainfall depth and intensity of the rain segments selected for the raindrop size distribution analysis.

\begin{tabular}{ccc}
\hline Intensity symbol & Depth $(\mathrm{mm})$ & ${\text { Intensity }\left(\mathrm{mm} \mathrm{h}^{-1}\right)}^{1.14}$ \\
\hline$I_{1}$ & 9.0 & 2.23 \\
$I_{2}$ & 17.5 & 3.82 \\
$I_{3}$ & 30.0 & 5.10 \\
$I_{4}$ & 40.0 & 9.93 \\
\hline$I_{5}$ & 78.0 & \\
\hline
\end{tabular}




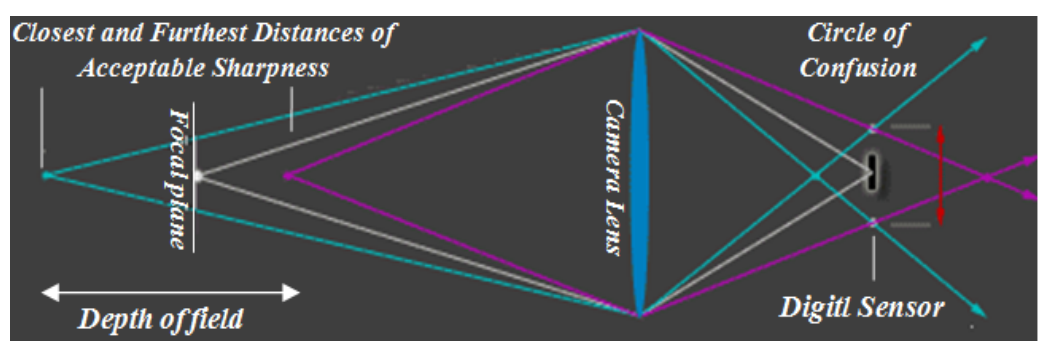

Focal Point
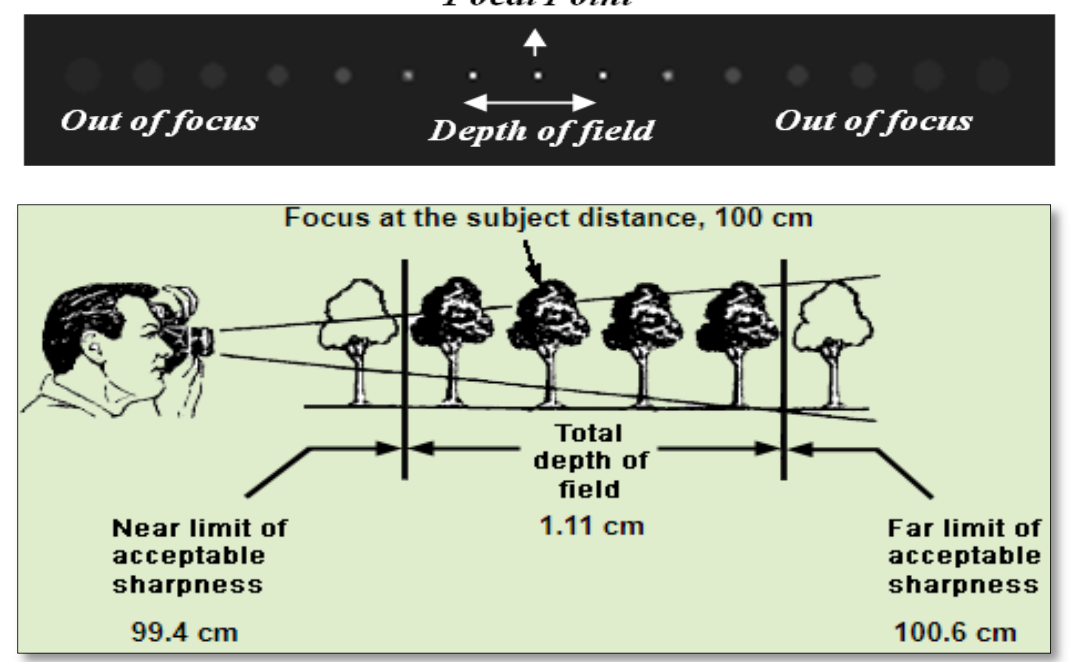

Fig. 2. A schematic of depth of field and gradual transition from focal point to out of focus areas in forward and backward of focal point (top) and calculated depth of field (DOF) for the camera using online depth of field calculator (WW.DOFMASTER.COM) (bottom).
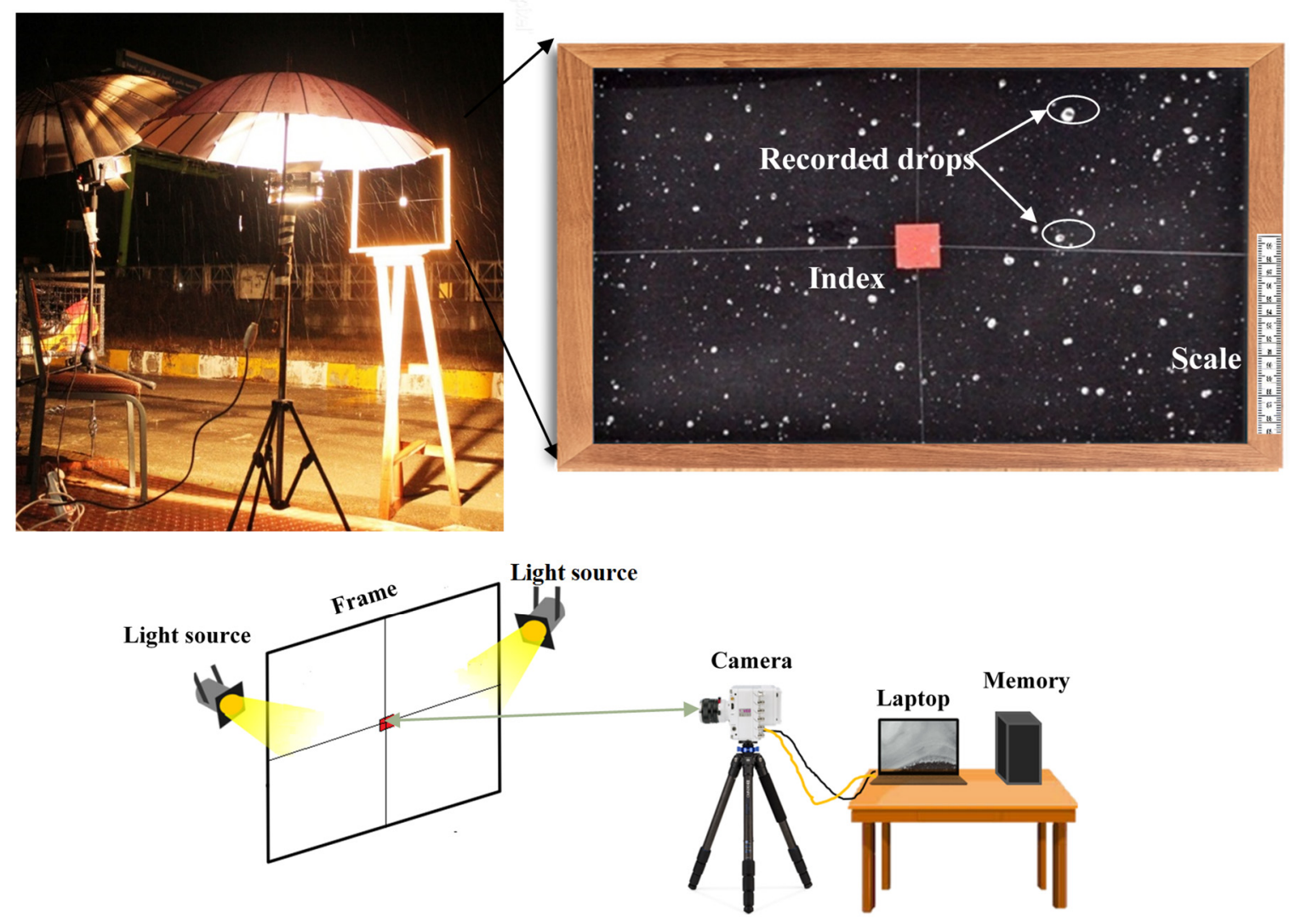

Fig. 3. A schematic view of the experimental set up and a sample of digitized image of drops captured by the camera. 

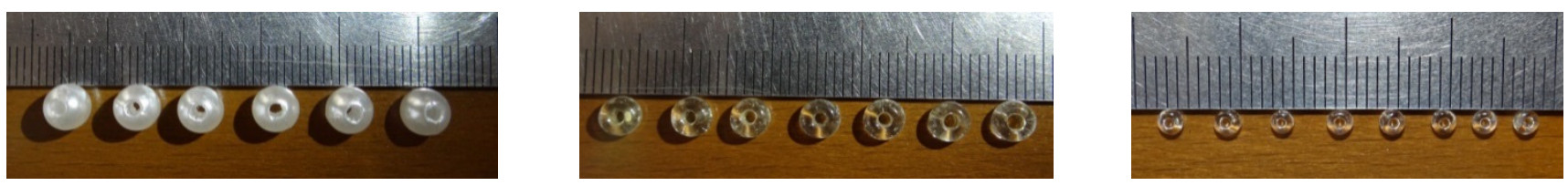

Fig. 4. Different sizes of glass beads used to calibrate the camera.

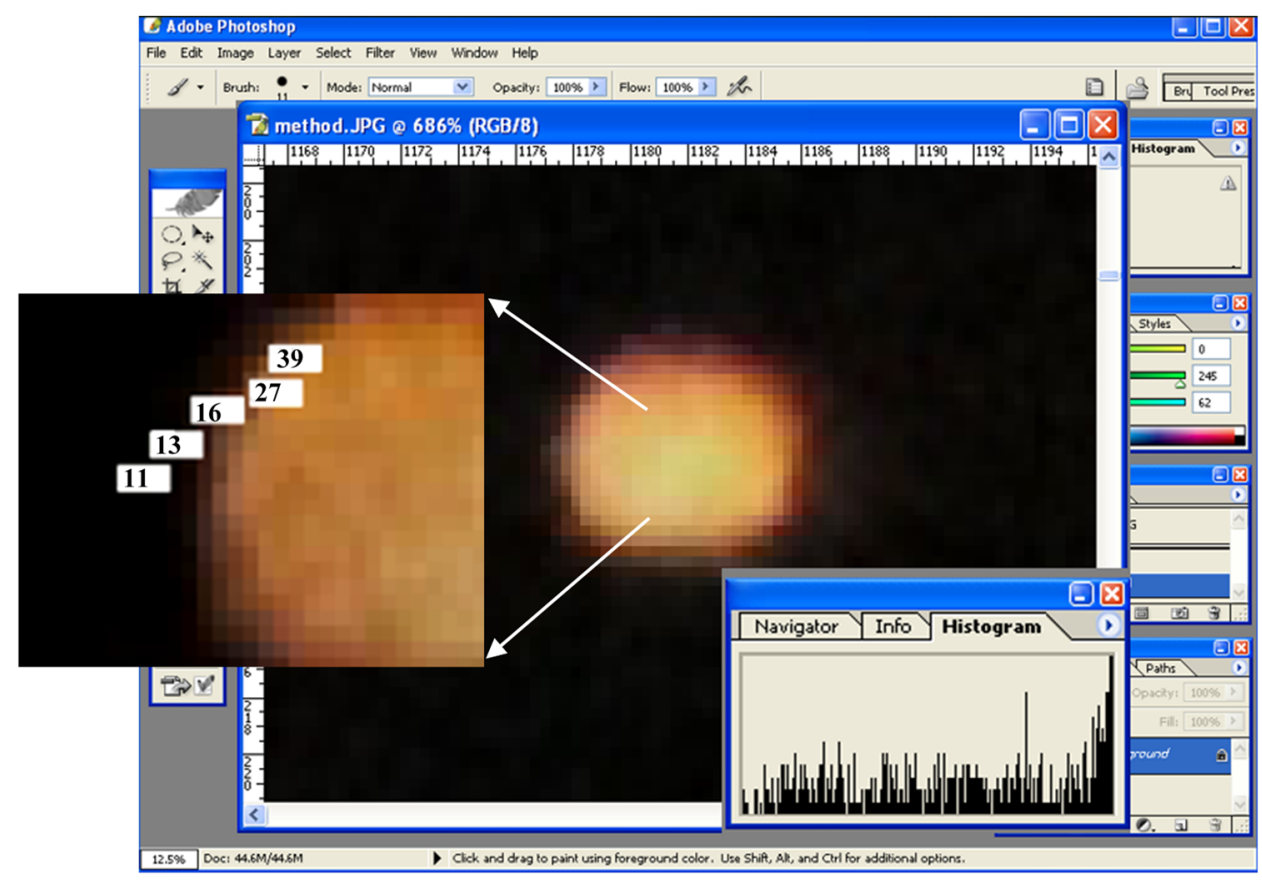

Fig. 5. Oscillation of gray level histogram for each particle which is near to light source, the gradual changes of color level at the edge of each particle and the intensity of each pixel, determined by brightness index.
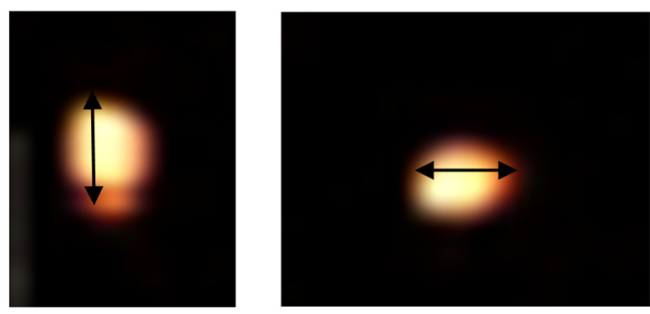

Fig. 6. Recorded drops which ablated and elongated due to oscillation.

The pixel value method was used to select a threshold of gray level for extracting objects from its background (Sudheer and Panda, 2000). The images were transmitted to a Photoshop Software Package and then the software identified the value of each pixel and extracted its gray level histogram. For recording smaller drops, the ISO (International Standards Organization) settings of the digital camera, or the sensitivity of the sensor, was automatically adjusted to a high level. Thus by approaching the light source, the noise in the image, and subsequently oscillation of histogram drastically increased (Fig. 5). Then, the gray-level histogram could not be used for denoting objects and backgrounds. As an indicator, we considered that a pixel, which has at least $10 \%$ difference in gray value over neighboring pixels, was exploited as a boundary pixel. The gray level at the edge of the particle changes more gradually as shown in Fig. 5. Further, to eliminate the depth of field error, some data located too far from or too near the lens of the camera were omitted. The intensity of each pixel was determined by brightness index
(B) in Photoshop. For in-focus particles, the B index has been near to $100 \%$ (Fig. 5). In this regard, the particles with smaller B (less than $80 \%$ ) were considered as out of focus and omitted from the dataset. Therefore, background and foreground raindrops were separated. Manual camera setting was optimal for almost all images except those for rain intensity $I_{l}$ that had too small drops and the AutoISO setting captured better and sharper drops.

Exner et al. (2019) indicated that droplet identification is based on their circular edges and central fluorescence intensity maxima. Therefore, the next stage was to detect and measure the diameter of drops. For diameter greater than $1 \mathrm{~mm}$, drops become increasingly oblate with size. Raindrops mostly fall with their minor axis oriented in the vertical, though some of them rarely elongated vertically owing to oscillations, collisions, or both (Fig. 6) as confirmed by Straka (2009). Hence, it was hard to measure the exact diameter of each ablated or elongated spheroid, the area of each bright object was determined 
using the area of each pixel multiplied by the number of pixels belong to each object. Consequently, the diameter of each object was determined and corresponding $D_{50}$ (i.e., the size that splits the distribution with half above and half below this diameter) for each intensity was also presented. Three repetitions were considered for each intensity. However, in $I_{4}$ and $I_{5}$ with more rainfall fluctuations, more data were taken for the analyses. The distribution curves were then produced based on available dataset.

Raindrops were classified and counted in size classes of $0.1 \mathrm{~mm}$ and summarized in Table 3 . To conduct the analyses, 1544 raindrops captured during photo snaps were analyzed. Then, a fitted Equation (1) with high coefficient of determination $\left(\mathrm{R}^{2}=0.9997\right)$ established between known-sized glass breads $d(\mathrm{~mm})$ and imagery-estimated sizes $D(\mathrm{~mm})$ by camera Canon 550D was used to obtain rain DSD.

$d=2.7028 D^{0.6735}$

Normal distribution of the data series was tested by the Kolmogorov-Smirnov method in SPSS 17.0 software to delete outline data. In addition, the corresponding statistical parameters were also calculated for each data series. The Duncan's Multiple Range test (DMRT) was further employed to see if there are specific differences in means between five mentioned intensities (Dafaallah, 2019).

\section{RESULTS AND DISCUSSION}

The volume of rainfall collected in the sampling gage and the calculated rainfall intensity used for the analyses of raindrop size distribution (DSD) are presented in Table 2 .

DSD was determined for five different rainfall intensities ranging from $1.14 \mathrm{~mm} \mathrm{~h}^{-1}$ to $9.93 \mathrm{~mm} \mathrm{~h}^{-1}$. The rainfall intensity greater than $4 \mathrm{~mm} \mathrm{~h}^{-1}$ is classified as heavy rain; intensities between $10 \mathrm{~mm} \mathrm{~h}^{-1}$ and $50 \mathrm{~mm} \mathrm{~h}^{-1}$ represent heavy showers (http://www.metoffice.gov.uk/weather). In Iran, rainfall intensities of $2.5 \mathrm{~mm} \mathrm{~h}^{-1}, 2.5 \mathrm{~mm} \mathrm{~h}^{-1}$ to $7.5 \mathrm{~mm} \mathrm{~h}^{-1}$ and more than 7.5 $\mathrm{mm} \mathrm{h}^{-1}$ are classified as slight, moderate, and heavy rains, respectively. As observed in Table 2, we covered a wide range of intensities in this study. Raindrops classified in size classes of $0.1 \mathrm{~mm}$ were summarized in Table 3 . The characteristics of the raindrops for selected rain intensities are summarized in Table 4.

As seen in Table 3, the photographic method could record drops in a wide range of diameters $(0.20$ to $6.00 \mathrm{~mm})$, which confirmed the results stated by Sudheer and Panda (2000) and $\mathrm{Hu}$ et al. (2006). They caught drops in sizes of around 0.5 to 10 mm produced by sprinkler nozzle through imaging. Sadeghi et al. (2013) also found out that the photographic method recorded a wider range of drop size rather than some other methods. According to their study, the flour pellet method recorded drops in a range of 0.58 to $5.17 \mathrm{~mm}$, while the stain method covered a range of $0.67 \mathrm{~mm}$ to $2.81 \mathrm{~mm}$ in slight to heavy rain intensities.

Table 2. Raindrop size distribution in five different intensities recorded through applying photographic technique.

\begin{tabular}{|c|c|c|c|c|c|c|c|c|c|c|c|}
\hline \multirow{2}{*}{$\begin{array}{l}\text { Drop diameter } \\
(\mathrm{mm})\end{array}$} & \multicolumn{5}{|c|}{ Drop numbers } & \multirow{2}{*}{$\begin{array}{l}\text { Drop diameter } \\
(\mathrm{mm})\end{array}$} & \multicolumn{5}{|c|}{ Drop numbers } \\
\hline & $I_{1}$ & $I_{2}$ & $I_{3}$ & $I_{4}$ & $I_{5}$ & & $I_{I}$ & $I_{2}$ & $I_{3}$ & $I_{4}$ & $I_{5}$ \\
\hline$<0.3$ & 11 & 0 & 0 & 0 & 0 & 3.1 & 0 & 0 & 0 & 0 & 0 \\
\hline 0.3 & 34 & 0 & 0 & 0 & 0 & 3.2 & 0 & 0 & 5 & 4 & 0 \\
\hline 0.4 & 28 & 0 & 0 & 0 & 4 & 3.3 & 1 & 0 & 4 & 1 & 7 \\
\hline 0.5 & 46 & 1 & 0 & 0 & 8 & 3.4 & 0 & 2 & 3 & 5 & 9 \\
\hline 0.6 & 88 & 2 & 0 & 0 & 10 & 3.5 & 0 & 0 & 4 & 0 & 6 \\
\hline 0.7 & 70 & 9 & 29 & 0 & 24 & 3.6 & 0 & 0 & 0 & 0 & 0 \\
\hline 0.8 & 17 & 6 & 11 & 2 & 65 & 3.7 & 2 & 3 & 5 & 0 & 8 \\
\hline 0.9 & 6 & 8 & 21 & 1 & 76 & 3.8 & 3 & 0 & 0 & 8 & 8 \\
\hline 1.0 & 0 & 7 & 4 & 4 & 13 & 3.9 & 0 & 4 & 0 & 7 & 5 \\
\hline 1.1 & 1 & 14 & 7 & 4 & 22 & 4.0 & 0 & 0 & 0 & 0 & 0 \\
\hline 1.2 & 0 & 11 & 2 & 9 & 6 & 4.1 & 0 & 2 & 3 & 1 & 0 \\
\hline 1.3 & 0 & 5 & 1 & 15 & 21 & 4.2 & 1 & 2 & 6 & 0 & 2 \\
\hline 1.4 & 0 & 6 & 1 & 22 & 4 & 4.3 & 0 & 3 & 1 & 7 & 7 \\
\hline 1.5 & 1 & 7 & 0 & 15 & 35 & 4.4 & 2 & 0 & 5 & 3 & 2 \\
\hline 1.6 & 0 & 2 & 4 & 13 & 33 & 4.5 & 0 & 0 & 0 & 1 & 8 \\
\hline 1.7 & 0 & 2 & 6 & 17 & 19 & 4.6 & 0 & 0 & 2 & 4 & 1 \\
\hline 1.8 & 1 & 14 & 8 & 11 & 6 & 4.7 & 0 & 0 & 4 & 2 & 5 \\
\hline 1.9 & 0 & 6 & 9 & 8 & 15 & 4.8 & 2 & 3 & 2 & 2 & 4 \\
\hline 2.0 & 1 & 1 & 2 & 7 & 21 & 4.9 & 0 & 1 & 0 & 2 & 12 \\
\hline 2.1 & 2 & 15 & 12 & 12 & 35 & 5.0 & 0 & 0 & 1 & 2 & 2 \\
\hline 2.2 & 0 & 1 & 2 & 12 & 2 & 5.1 & 2 & 0 & 1 & 0 & 0 \\
\hline 2.3 & 0 & 4 & 2 & 2 & 29 & 5.2 & 0 & 0 & 0 & 0 & 2 \\
\hline 2.4 & 0 & 3 & 0 & 7 & 12 & 5.3 & 0 & 0 & 0 & 0 & 1 \\
\hline 2.5 & 0 & 4 & 4 & 9 & 16 & 5.4 & 0 & 0 & 0 & 0 & 2 \\
\hline 2.6 & 0 & 1 & 0 & 10 & 4 & 5.5 & 0 & 0 & 0 & 0 & 2 \\
\hline 2.7 & 1 & 1 & 0 & 5 & 8 & 5.6 & 0 & 0 & 0 & 0 & 0 \\
\hline 2.8 & 2 & 2 & 3 & 13 & 10 & 5.7 & 0 & 0 & 0 & 0 & 0 \\
\hline 2.9 & 0 & 2 & 0 & 10 & 24 & 5.8 & 0 & 0 & 0 & 0 & 2 \\
\hline 3.0 & 0 & 1 & 10 & 5 & 0 & 5.9 & 0 & 0 & 0 & 0 & 0 \\
\hline & & & & & & 6.0 & 0 & 0 & 0 & 0 & 4 \\
\hline
\end{tabular}

$I_{1}$ to $I_{5}$ respectively show the intensity of $1.14 \mathrm{~mm} \mathrm{~h}^{-1}, 2.23 \mathrm{~mm} \mathrm{~h}^{-1}, 3.82 \mathrm{~mm} \mathrm{~h}^{-1}, 5.10 \mathrm{~mm} \mathrm{~h}^{-1}$, and $9.93 \mathrm{~mm} \mathrm{~h}^{-1}$. 
Table 3. Descriptive statistic of natural raindrop size distribution in five intensities.

\begin{tabular}{lccccc}
\hline \multirow{2}{*}{ Descriptive statistic } & & Intensity $\left(\mathrm{mm} \mathrm{h}^{-1}\right)$ & 5.10 & 9.93 \\
\hline Minimum (mm) & 1.14 & 2.23 & 3.82 & 0.800 & 0.400 \\
Maximum (mm) & 0.200 & 0.500 & 0.700 & 5.000 & 6.000 \\
Standard deviation (mm) & 5.100 & 4.900 & 5.100 & 1.017 & 1.262 \\
Mean (mm) & 0.789 & 1.049 & 1.303 & 2.322 & 1.975 \\
Median (mm) & 0.747 & 1.860 & 2.049 & 2.100 & 1.600 \\
Skewness & 0.600 & 1.600 & 1.800 & 0.918 & 1.152 \\
Kurtosis & 3.935 & 1.218 & 0.722 & -0.017 & 0.645 \\
\hline
\end{tabular}

Table 4. Characteristics of the raindrops for selected rain intensities; different letter in the right column means that the characteristics are significantly different according to the Duncan test.

\begin{tabular}{cc}
\hline Intensity $\left(\mathrm{mm} \mathrm{h}^{-1}\right)$ & Mean and Standard Error $(\mathrm{mm})$ \\
\hline 1.14 & $0.987 \pm 0.082^{\mathrm{c}}$ \\
2.23 & $1.467 \pm 0.082^{\mathrm{b}}$ \\
3.82 & $1.747 \pm 0.082^{\mathrm{a}}$ \\
5.10 & $1.720 \pm 0.082^{\mathrm{a}}$ \\
9.93 & $1.433 \pm 0.082^{\mathrm{b}}$ \\
\hline
\end{tabular}

Besides, they reported that $D_{50}$ ranged from $0.92 \mathrm{~mm}$ to 2.09 $\mathrm{mm}$ in the flour-pellet method and $1.12 \mathrm{~mm}$ to $1.75 \mathrm{~mm}$ in stain methods in similar intensities.

Despite the elimination of some data recorded in the image, drop numbers were found to be sufficient for the analysis. As mentioned before, we applied the drop distribution for drops located at an appropriate distance from the camera lens to increase the measurement accuracy. Hence, the data distribution was tended to focus on the center of the image. The results found by Oberdier (1984) and Koh et al. (2001) confirmed similar finding. The drop diameters recorded in this study were in the range of $<0.2 \mathrm{~mm}$ to $5.1 \mathrm{~mm}$, which was similarly reported by Sheppard and Joe (1994). Scrutiny in images showed that tiny drops (smaller than a pixel of $<0.09$ $\mathrm{mm}$ as result of spacing 18700000 pixels in a $300 \times 500-\mathrm{mm}$ Frame) recorded in each image in different intensities were hidden in pre-interprets. The tiny drops did not reflect the light drastically, even if they were located in the focal point. So, this made the interpreter to question whether it referred to tiny drops or the camera was out of focus. On the other hand, the size of the pixels was larger than the tiny dimension drops, so denotation of a particle in each pixel was rather impossible because of the image noise.

The One Way Analysis of Variance (ANOVA) showed that the variation of rainfall intensity significantly influences raindrop sizes $(\mathrm{p}<5 \%)$. This means that at different intensities, the raindrop sizes are significantly different. It was observed that the increasing rainfall intensity did not necessarily correspond to increasing drop sizes (Table 3). This might be attributed to the fact that the drops had a higher amount of contact with each other at high rainfall intensities. The larger drops have higher velocity and subsequently higher kinetic energy. That is why they contact each other with more severity and disjoint. Therefore, more droplets are observed. On the other hand, the rainfall events usually coincided with drastic winds in the Mazandaran climate resulting in an intensification of drop incidents. The results of the comparison of five mentioned intensities, using Duncan test, showed that the two intensities of $I_{3}$ and $I_{4}$ gave a larger percentage of the large drop size range. Therefore, both of them set in the class of "a" (Table 4).
Meanwhile, two intensities of $I_{2}$ and $I_{5}$ were set in the second rank, i.e. class of "b". This result proved that increasing the rainfall intensity led to an increase in median volume diameter, $D_{50}$, as a widely used index, to a special bound and tended to skew the DSD curves to the left. Then $D_{50}$ decreased when the intensity increased. In this state, the skew of the DSD curves tended to the right. As a result, the study of DSD has shown that the majority of drops are of the size of 1 to $2 \mathrm{~mm}$. This might be due to the fact that drops larger than about $5.5 \mathrm{~mm}$ are unstable and break up, although larger drops can exist for short periods as reported by Lavergnat and Gole (1998). These studies showed that when large drops break up, many small drops are produced in the size of 1 to $2 \mathrm{~mm}$, predominantly.

\section{CONCLUSION REMARKS}

The raindrop size distribution was analyzed under natural conditions using images captured by a standard DSLR camera. The drop diameters recorded in this study were in the range of $<0.2$ to $5.1 \mathrm{~mm}$. The results showed that moderate rainfall intensities gave a higher percentage of the large drop size range. Increasing rainfall intensity led to an increase in $D_{50}$. In Mazandaran climatic conditions, the majority of drops in natural rainfall were observed in the size of 1 to $2 \mathrm{~mm}$. The results indicated that a standard camera could be considered as a practical, available, and not so expensive as other modern devices to record raindrop size during the outdoor observations. It had a high ability to identify drops with acceptable accuracy and could provide sufficient information for the rainfall properties. The high variability of drop size distribution (DSD) in different intensities achieved for the study area can be practically utilized by researchers working in the field of soil erosion and meteorology. It is obvious that some other devices like a disdrometer or radar might provide much more details with higher accuracy and less time consumption. However, the expectation from the photogrammetry as a more accessible methodology in lowequipped countries would be also limited compared to much more sophisticated and expensive devices. Additional studies in other climatic conditions and different areas and using alternative graphics software for photo processing are required to reach a comprehensive conclusion. 

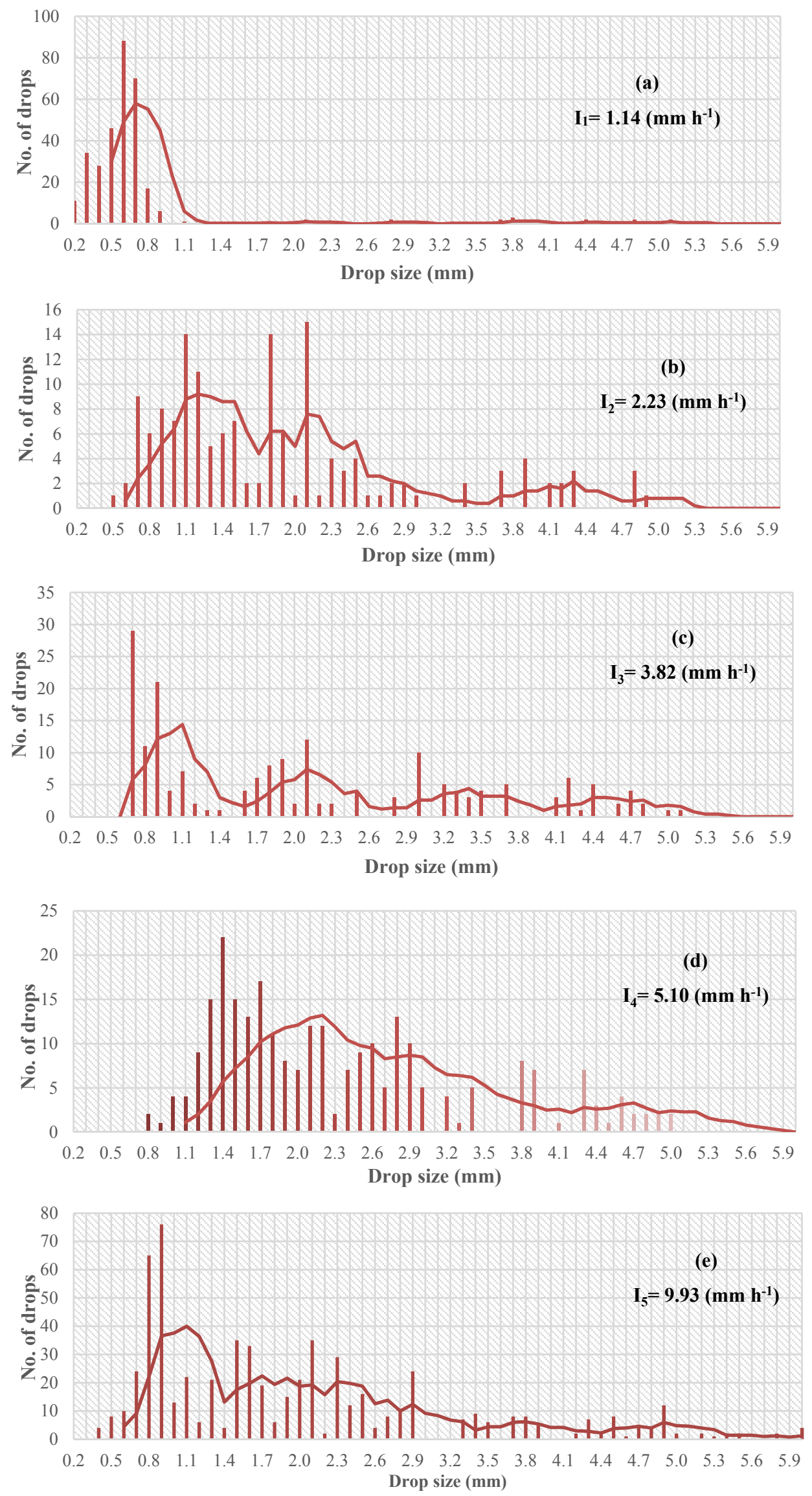

Fig. 7. Drop size distribution curves in different intensities. 
Acknowledgements. The present paper has been prepared based on the facilities provided by Tarbiat Modares University, Iran during the first author's MSc Program. The partial support of the Agrohydrology Research Group of Tarbiat Modares University (grant No. IG-39713), Iran, to the corresponding author is also thanked. The authors also acknowledge Dr. Behzad Shokati for his great support and for comments that greatly improved the manuscript.

\section{REFERENCES}

Angulo-Martínez, M., Beguería, S., Kyselý, J., 2016. Use of disdrometer data to evaluate the relationship of rainfall kinetic energy and intensity (KE-I). Sci. Total Environ., 568, 83-94. https://doi.org/10.1016/j.scitotenv.2016.05.223.

Asadpour, F., Habibi, A., 2015. Strategies for climatic design for sustainable urban housing development (case study of Nur City, Mazandaran, Iran. Sci. J. (CSJ), 36, 6, 653-654.

Bringi, V.N., Chandrasekar, V., Hubbert, J., Gorgucci, E., Randeuand, W.L., Schoenhuber, M., 2003. Raindrop size distribution in different climatic regimes from disdrometer and dual-polarized radar analysis. Atmos. Res., 60, 354-365. https://doi.org/10.1175/1520-0469

Chang, X., Zheng, K., Xie, D., Shu, X., Xu, K., Chen, W., Li, B., $\mathrm{Wu}, \mathrm{Ch} ., 2019$. In situ image acquisition and measurement of microdroplets based on delay triggering. Micromachines, 10, 2, 148. https://doi.org/10.3390/mi10020148

Chang, W.-Y., Lee, G., Jou, B. J.-D., Lee, W.-C., Lin, P.-L., $\mathrm{Yu}, \mathrm{C} .-\mathrm{K} ., 2020$. Uncertainty in measured raindrop size distributions from four types of collocated instruments. Remote Sens., 12, 1167. https://doi.org/10.3390/rs12071167

Cruvinel, P.E., Vieira, S.R., Crestana, S., Minatel, E.R., Mucheroni, M.L., Neto, A.T., 2017. Image processing in automated measurements of raindrop size and distribution. Comput. Electron. Agr., 23, 3, 205-217. https://doi.org/10.1016/S0168-1699(99)00043-5

Dafaallah, A., 2019. 12 Duncan's multiple range test (DMRT). 10.13140/RG.2.2.16262.93764.

Das, S.K., Konwar, M., Chakravarty, K., Deshpande, S.M., 2017. Raindrop size distribution of different cloud types over the western ghats using simultaneous measurements from micro-rain radar and disdrometer. Atmos. Res., 186, 72-82. https://doi.org/10.1016/j.atmosres.2016.11.003

D'Adderio, L.P., Porcù, F., Tokay, A., 2018. Evolution of drop size distribution in natural rain. Atmos. Res., 200, 70-76. https://doi.org/10.1016/j.atmosres.2017.10.003

DeBoer, D. W., Monnens, M. J., Kincaid, D.C., 2001. Measurement of sprinkler drop size. Appl. Eng. Agric., 17, 1, 11-15. https://doi.org/10.13031/2013.1931

Eigel, J.D., Moore, I.D., 1983. A simplified technique for measuring raindrop size and distribution. Trans. ASAE., 26, 4, 1079-1084. https://doi.org/10.13031/2013.34080

Exner, T., Beretta, C.A., Gao, Q., Afting, C., Romero-Brey, I., Bartenschlager, R., Fehring, L., Poppelreuther, M., Fuellekrug, J., 2019. Lipid droplet quantification based on iterative image processing. J. Lipid Res., 60, 1333-1344, https://doi.org/10.1194/jlr.D092841

Frank, G., Härtl, T., Tschiersch, J., 1994. The pluviospectrometer: Classification of falling hydrometeors via digital image processing. Atmos. Res., 34, 1-4, 367-378. https://doi.org/10.1016/0169-8095 (94)90103-1

Hall, M.J., 1970. Use of the stain method in determining the drop size distribution of coarse liquid sprays. Trans. ASAE., 13, 33-37. https://doi.org/10.13031/2013.38528

Hu, B., Angeli, P., Matar, O.K., Lawrence, C.J., Hewitt, G.F.,
2006. Evaluation of drop size distribution from chord length measurements. J. Agric. Biotech., 52, 3, 931-939. https://doi.org/10.1002/aic.10714

Illingworth, A.J., Stevens, C.J., 1987. An optical disdrometer for the measurement of raindrop size spectra in windy conditions. J. Atmos. Ocean Technol., 4, 411-421. https://doi.org/10.1175/1520-0426

Islam, T., Rico-Ramirez, M.A., Han, D., Srivastava, P.K., 2012. A Joss-Waldovgel disdrometer derived rainfall estimation study by collocated tipping bucket and rapid response rain gauges. Atmospheric Sci. Lett., 13, 2, 139-150. https://doi.org/10.1002/asl.376

Jash, D., Resmi, E.A., Unnikrishnan, C.K., Sumesh, R.K., Sreekanth, T.S., Sukumar, N., Ramachandran, K.K., 2019. Variation in rain drop size distribution and rain integral parameters during southwest monsoon over a tropical station: An inter-comparison of disdrometer and micro rain radar. Atmos. Res., 217, 24-36. https://doi.org/10.1016/j.atmosres.2018.10.014

Jayawardena, A.W., Rezaur, R.B., 2000. Drop size distribution and kinetic energy load of rainstorms in Hong Kong. Hydrol. Process., 14, 6, 1069-1082.

Jwa, M., Jin, H.G., Lee, J., Moon, S., Baik, J.J., 2020. Characteristics of raindrop size distribution in Seoul, South Korea according to rain and weather types. APJAS, 1-13. DOI: $10.1007 / \mathrm{s} 13143-020-00219-\mathrm{w}$

Kathiravelu, G., Lucke, T., Nichols, P., 2016. Raindrop measurement techniques: a review. Water, 8, 29, 1-20. https://doi.org/10.3390/w8010029

Kavian, A., Mohammadi, M., Cerda, A., Fallah, M., Abdollahi, Z., 2018. Simulated raindrop's characteristic measurements. A new approach of image processing tested under laboratory rainfall simulation. Catena, 167, 190-197. https://doi.org/10.1016/j.catena.2018.04.034

Khaledian, H., Shahoe, S.S., 2006. Evaluating of natural raindrop size distribution in Kordestan Province. J. Agric. Sci., 37, 6, 1093-1102. (In Persian.)

King, B.A., Winward, T.W., Bjorneberg, D.L., 2014. Comparison of drop size and velocity measurements by a laser precipitation meter and low-speed photography or an agriculture sprinkler. Appl. Eng. Agric., 30, 3, 413-421. [eprints.nwisrl.ars.usda.gov/1543/1/1500.pdf]

Koh, K.U., Kim, J.Y., Lee, S.Y., 2001. Determination of in focus criteria and depth of field in image processing of spray particles. At. Sprays, 11, 4, 317-333. https://doi.org/10.1615/AtomizSpr.v11.i4.20

Kuthirummal, S., Nagahara, H., Changyin, Z., Nayar, S.K., 2010. Flexible depth of field photography. IEEE PAMI., 33, 1, 58-71. https://doi.org/10.1109/TPAMI.2010.66

Lavergnat, J., Gole, P., 1998. A stochastic raindrop time distribution model. J. Appl. Meteorol., 37, 805-818. https://doi.org/10.1175/1520-0450(1998)037

Laws, J.Q., Parsons, D.A., 1943. The relation of raindrop size to intensity. Trans. American Geophysical Union, 26, 452460. https://doi.org/10.1029/TR024i002p00452

Lilley, M., Lovejoy, S., Desaulniers-Soucy, N., Schertzer, D., 2006. Multifractal large number of drops limit in rain. J. Hydrol., 328, 1-2, 20-37. https://doi.org/10.1016/j.jhydrol.2005.11.063

Lima, J., Silva, V.P., Lima, M., Abrantes, J.B., Montenegro, A.A., 2015. Revisiting simple methods to estimate drop size distributions: a novel approach based on infrared thermography. J. Hydrol. Hydromech., 63, 3, 220-227. https://doi.org/10.1515/johh-2015-0025

Luo, C.G., Xiao, X., Martínez-Corral, M., Chen, C.W., Javidi, 
B., Wang, Q.H., 2013. Analysis of the depth of field of integral imaging displays based on wave optics. Opt. Express., 21, 25, 1-11. https://doi.org/10.1364/OE.21.031263

Marshall, J.S., Palmer, W.M., 1948. The distribution of raindrops with size. JAMC, 5, 165-166. https://doi.org/10.1175/1520-0469

McIsaac, G.F., 1990. Apparent geographic and atmospheric influences on raindrop sizes and rainfall kinetic energy. J. Soil Water Conserv., 45, 663-666. http://www.jswconline.org/content/45/6/663.abstract

Meshesha, D., Tsunekawa, A., Ayehu, N., 2017. Application of optical disdrometer to characterize simulated rainfall and measure drop size distribution. Geophys. Res. Abstr., 19, EGU2017116. https://doi.org/10.1080/02626667.2018.1521522

Molina-Sanchis, I., Lázaro, R., Arnau-Rosalén, E., Calvo-Cases, A., 2016. Rainfall timing and runoff: the influence of the criterion for rain event separation. J. Hydrol. Hydromech., 64, 3, 226-236. https://doi.org/10.1515/johh-2016-0024

Oberdier, L.M., 1984. An instrumentation system to automate the analysis of fuel-spray images using computer vision. In: Tishkoff, J., Ingebo, R., Kennedy, J. (Eds.): Liquid Particle Size Measurement Techniques. ASTM International, West Conshohocken, PA, USA, pp. 123-136. https://doi.org/10.1520/STP32621S

Perwass, C., Wietzke, L., 2012. Single lens 3D-camera with extended depth-of-field. In: Proc. XVII conference on $\mathrm{Hu}-$ man Vision and Electronic Imaging, February 9, 2012. https://doi.org/10.1117/12.909882]

Sadeghi, S.H., Abdollahi, Z., Khaledi Darvishan, A., 2013. Experimental comparison of some techniques for estimating natural raindrop size distribution on the south coast of the Caspian Sea, Iran. Hydrol. Sci. J., 58, 6, 1-9. https://doi.org/10.1080/02626667.2013.814917

Salles, C., Poesen, J., 1999. Performance of an optical spectro pluiviometer in measuring basic rain erosivity characteristics. J. Hydrol., 218, 142-156. https://doi.org/10.1016/S00221694(99)00031-1

Salvador, R., Baustista-Capetillo, C., Burguete, J., Zapata, N., Serreta, A., Playán, E., 2009. A photographic method for drop characterization in agricultural sprinklers. Irrig. Sci., 27, 4, 307-317. https://doi.org/10.1007/s00271-009-0147-2

Sawant, S., Ghonge, P.A., 2015. Estimation of raindrop analysis using image processing. Int. J. Sci. Res., 4, 1, 19811986. https://www.ijsr.net/archive/v4i1/SUB15661.pdf

Seginer, I., 1963. Water distribution from medium pressure sprinklers. Journal of the Irrigation and Drainage Division, 89, 2, 13-29. https://cedb.asce.org/CEDBsearch/record.jsp?dockey=0012934

Serio, M.A., Carollo, F.G., Ferro, V., 2019. Raindrop size distribution and terminal velocity for rainfall erosivity studies. A review. J. Hydrol., 576, 210-228. https://doi.org/10.1016/j.jhydrol.2019.06.040

Sijs, R., Kooij, S., Holterman, H.J., van de Zande, J., Bonn, D., 2021. Drop size measurement techniques for sprays: Comparison of image analysis, phase Doppler particle analysis, and laser diffraction. AIP Advances, 11, 1, Article Number: 015315. https://doi.org/10.1063/5.0018667

Sheppard, B.E., Joe, P.I., 1994. Comparison of raindrop size distribution measurements by a Joss-Waldovgel disdrometer, a PMS 2DG spectrometer and a Poss Doppler radar. J. Atmos. Ocean Technol., 11, 874-887. https://doi.org/10.1175/1520-0426(1994)011
Solomon, K.H., Kincaid, D.C., Bezdek, J.C., 1985. Drop size distribution for irrigation spray nozzles. Trans. ASAE., 28, 6, 1966-1974. https://doi.org/10.13031/2013.32550

Sreekanth, T.S., Varikoden, H., Sukumar, N., Kumar, G.M., 2017. Microphysical characteristics of rainfall during different seasons over a coastal tropical station using disdrometer. Hydrol. $\quad$ Process., 31, 14, 2556-2565. https://doi.org/10.1002/hyp.11202

Straka, J.M., 2009. Cloud and Precipitation Microphysics: Principles and Parameterizations. Cambridge University Press, $386 \mathrm{p}$.

Steinmann, T., Casas, J., Braud, P., David, L., 2021. Coupled measurements of interface topography and three-dimensional velocity field of a free surface flow. Exp. Fluids, 62, 1, 1-16. https://doi.org/10.1007/s00348-020-03115-1

Sudheer, K.P., Panda, R.K., 2000. Digital image processing for determining drop sizes from irrigation spray nozzles. Agric. Water Manag., 45, 159-167. https://doi.org/10.1016/S03783774(99)00079-7

Sulochana, Y., Rao, T.N., Sunilkumar, K., Chandrika, P., Raman, M.R., Rao, S.V.B., 2016. on the seasonal variability of raindrop size distribution and associated variations in reflectivity - rainrate relations at Tirupati, a tropical station. J. Atmos. Sol. Terr. Phys., 147, 98-105. https://doi.org/10.1016/j.jastp.2016.07.011

Tang, Q., Xiao, H., Guo, C., Feng, L., 2014. Characteristics of the raindrop size distributions and their retrieved polarimetric radar parameters in Northern and Southern China. Atmos. Res., 135-136, 59-75. https://doi.org/10.1016/j.atmosres.2013.08.003

Thurai, M., Bringi, V. N., Petersen, W. A., 2009. Rain microstructure retrievals using 2-D video disdrometer and C-band polarimetric radar. Adv. Geosci., 20, 13-18. https://doi.org/10.5194/adgeo-20-13-2009

Thurai, M., Gatlin, P., Bringi, V., Petersen, W., Kennedy, P., Notaros, B., Carey L., 2017. Towards completing the raindrop size spectrum: Case studies involving 2D-video disdrometer, droplet spectrometer, and polarimetric radar measurements. J. Appl. Meteorol. Climatol., 56, 4, 877-896. https://doi.org/10.1175/JAMC-D-16-0304.1

Wang, G., Zhou, R., Zhaxi, S., Liu, S., 2021. Raindrop size distribution measurements on the Southeast Tibetan Plateau during the STEP project. Atmos. Res., 249, Article Number: 105311. https://doi.org/10.1016/j.atmosres.2020.105311

You, C.H., Lee, D.I., Kang, M.Y., Kim, H.J., 2016. Classification of rain types using drop size distributions and polarimetric radar: Case study of a 2014-flooding event in Korea. Atmos. Res., 181, 211-219. https://doi.org/10.1016/j.atmosres.2016.06.024

Yousefi, S., Sadeghi, S.H.R., Mirzaee, S., Van der Ploeg, M., Keesstra, S., Cerdà, A., 2018. Spatio-temporal variation of throughfall in a hyrcanian plain forest stand in Northern Iran, J. Hydrol. Hydromech., 66, 1, 97-106. DOI: 10.1515/johh-2017-0034

Zhang, G., Vivekanandan, J., Brandes, E., 2001. A method for estimating rain rate and drop size distribution from polarimetric radar measurements. IEEE Trans. Geosci. Remote Sens., 39, 4, 830-841. https://doi.org/10.1109/36.917906

Received 22 October 2020 Accepted 1 March 2021 